\title{
LA COLECTIVIDAD BRITÁNICA EN VALPARAÍSO DURANTE LA PRIMERA MITAD DEL SIGLO XX**
}

En este trabajo analizamos la importancia de la colectividad británica en el desarrollo económico de Valparaíso (Chile), pese a su limitada presencia, durante la primera mitad del siglo XX. Se hace notar el predominio de la colectividad el comercio internacional como también en la actividad industrial especialmente en aquellas que poseían un mayor desarrollo tecnológico.

La disminución de la importancia económica y también demográfica de la colectividad británica en Valparaíso, a partir de la década de 1920, se relaciona directamente con la perdida de influencia británica, en nuestro Continente, luego de la Primera Guerra Mundial.

Palabras clave: Inmigración, viajeros ingleses, comercio, industria, colectividad británica.

In this work we analyze the importance of the british immigrants in the economic development of Valparaiso during the first half of twenty century. We highlight their predominance in the international trade and in the industrial activity especially those that reveal a high technological development.

The economic and demographic decline of the british immigrants from 1920 is in close relation with the lost of the british influence in Latin America after the First World War.

Keys words: Immigration, british travellers, trade, industry, british in Valparaíso.

\section{INTRODUCCIÓN}

La relevancia de la presencia británica en Valparaíso y en todo Chile se hizo notoria, y en un nivel hegemónico, desde el momento mismo de la independencia. Uno de los principales logros que tuvo este acontecimiento fue la apertura al comercio internacional, con lo cual el dominio económico ejercido por los británicos se hizo notar de inmediato en nuestras costas y aumentando en la medida que avanzaba el siglo. Dadas estas circunstancias no es extraño que la colectividad británica apareciera como la más numerosa de las colectividades europeas hasta 1885, siendo superada definitivamente a partir del censo de 1895 (ver cuadro $\mathrm{N}^{\circ} 1$ ). Efectivamente la

* Decano de la Facultad de Filosofía y Educación. Pontificia Universidad Católica de Valparaíso. Correo electrónico: bestrada@ucv.cl

** Es parte del proyecto FONDECYT N 1020978. 
década de 1880 marca un hito en la participación británica como también en la importancia del puerto de Valparaíso en el comercio internacional ${ }^{1}$.

\section{CUADRO No 1}

COLECTIVIDADES EUROPEAS MÁS IMPORTANTES. DEPARTAMENTO DE VALPARAÍSO 1875-1952

\begin{tabular}{lrrrrrrrr}
\hline Nacionalidades & 1875 & 1885 & 1895 & 1907 & 1920 & 1930 & 1940 & 1952 \\
\hline Alemanes & 1.134 & 1.165 & 1.396 & 2.055 & 1.440 & 1.503 & 2.162 & 1.568 \\
Franceses & 986 & 819 & 1.097 & 1.003 & 791 & 549 & 377 & 375 \\
Españoles & 346 & 562 & 1.317 & 3.463 & 3.496 & 3.040 & 3.233 & 2.836 \\
Británicos & 1.785 & 1.478 & 1.974 & 2.053 & 1.799 & 1.322 & 693 & 419 \\
Italianos & 807 & 1.449 & 2.264 & 2.985 & 2.837 & 2.834 & 2.848 & 2.632 \\
Otros extranjeros & 1.863 & 2.189 & 2.252 & 3.071 & 3.080 & 3.747 & 4.351 & 4.762 \\
Total extranjeros & 6.921 & 7.662 & 10.302 & 14.630 & 13.443 & 12.995 & 13.664 & 11.592 \\
\hline
\end{tabular}

Fuente: Censos de la República de Chile para los años indicados.

Existen destacadas investigaciones centradas en la importancia del comercio británico en el desarrollo de Valparaíso para el siglo XIX que nos permiten conocer de manera muy apropiada el significado que esta presencia tuvo para la economía local como también para conocer el papel que desempeñó este emergente puerto en el proceso expansivo británico ${ }^{2}$. Por otro lado, conocemos también destacados trabajos referentes a los vínculos que tuvo Valparaíso con el desarrollo de la explotación del salitre y al significado que este importante recurso natural tuvo para la economía chilena como también para la inglesa ${ }^{3}$. Sin embargo, exceptuando las sugerentes y sólidas investigaciones de Ricardo Couyoumdjian, para el siglo $\mathrm{XX}^{4}$ no ha existido mayor interés por parte de los especialistas lo cual se justificaría en virtud de la evidente decadencia de la presencia británica en nuestro proceso económico luego de la Primera Guerra Mundial. A nuestro parecer, reconociendo la decadencia de la participación británica para el período señalado, es pertinente

1 Cavieres, Eduardo. Comercio Chileno y Comerciantes Ingleses 1810-1880: Un Ciclo de Historia Económica, Serie Monografías Históricas $\mathrm{N}^{\circ}$ 2, Instituto de Historia Universidad Católica de Valparaíso, 1988.

2 A la ya señalada obra de E. Cavieres habría que agregar los trabajos de John Mayo, British Merchants and Chilean Development, 1851-1886, Westview Press, Boulder 1987 y Daniel Zimmerman, "British Influence in the Modernization of Chile, 1860-1914", Ph.D. Dissertation, University of New Mexico, 1977.

3 Entre las más importantes investigaciones al respecto debemos señalar a Thomas O’Brian, The Nitrate Industry and Chile's Crucial Transition, 1870-1891, New York, 1982; Michael Monteon, Chile in the Nitrate Era. The Evolution of Economic Dependence, 1880-1930, University of Wisconsin Press, 1982.

4 Nos referimos a Chile y Gran Bretaña durante la Primera Guerra Mundial y la Postguerra, Editorial Andrés Bello, 1886 y a "El Alto Comercio de Valparaíso y las Grandes Casas Extranjeras, 1880-1930. Una Aproximación", Historia, Vol. 33. 2000, 84. En todo caso ambos trabajos no cubren todo el período que nos interesa: 1900-1950. 
no desconocer su presencia y precisar su relevancia en el devenir de la ciudadpuerto de Valparaíso durante un período de su historia poco estudiado pero muy importante para comprender su presente sobrecargado de añoranzas, nostalgias y olvidos; con lo cual se desconoce un pasado construido dentro de un proceso histórico que no tenemos presente al momento de analizar nuestra evolución. Se rescatan trazos y se marginan etapas, construyendo una historia sesgada que es más bien una leyenda. Es común escuchar sobre la importancia de Valparaíso durante el siglo XIX y suponer que tal sitial le corresponde también para el siglo XX como un simple legado sin ningún análisis elemental de los procesos históricos correspondientes como el desarrollo tecnológico y su impacto en los sistemas de transporte, los procesos económicos internacionales y la propia evolución y transformación interna del país. En este trabajo queremos revisar la participación que tuvieron los británicos no solo como activos comerciantes e industriales, sino como habitantes de una ciudad que se va transformando en un proceso que significó cambios importantes en su rol portuario dentro del contexto nacional como también internacional. En esta evolución se irá advirtiendo un cambio dentro de la colectividad en cuanto a que comenzamos a distinguir de modo más nítido a los ingleses de Valparaíso, es decir, aquellos que se quedaron y no solo estuvieron de paso. Aquellos que construyeron sus familias en este lugar y se transformaron en residentes definitivos. También están los otros que solo vinieron como consecuencia de sus actividades laborales pero que también con su accionar aportaron a la impronta de la ciudad.

\section{TESTIMONIOS DE VIAJEROS BRITÁNICOS DE COMIENZOS DEL SIGLO XIX}

Es pertinente recordar, respecto a la presencia británica, los interesantes testimonios que existen de numerosos viajeros ingleses que nos visitaron al inicio de nuestra vida republicana. Dichos relatos nos sirven para conocer aspectos importantes del Valparaíso de la época como también de acontecimientos nacionales, que escritos con la perspectiva foránea adquieren un valor histórico destacable para comprender el período afectado ${ }^{5}$.

Entre los primeros británicos que nos visitaron debemos mencionar al capitán escocés Basil Hall, quien llegó a Valparaíso a fines de 1820, con lo cual pudo disfrutar de las típicas fiestas de la época, las que describió con mucha perspicacia en sus relatos ${ }^{6}$ aunque quedó desilusionado por la primera impresión que le dejó la ciudad al llegar ${ }^{7}$. Similares percepciones tuvo también Richard Longeville Vowell,

5 Baldomero Estrada, "Los Relatos de Viajeros como Fuente Histórica: Visión de Chile y Argentina en Cinco Viajeros Ingleses (1817-1835)", en: Revista de Indias, Vol. XLVII, $\mathrm{N}^{\circ} 180$ mayo-agosto 1987, Consejo Superior de Investigaciones Científicas, Madrid, 631-666.

6 Basilio Hall, El General San Martín en el Perú, Biblioteca de la Nación, Buenos Aires 1917.

7 Basilio Hall, op. cit, al respecto señala: "Después de un viaje peligroso y prolongado, los marinos se hallan dispuestos a considerar deliciosa cualquier costa y probablemente por tal causa, los primeros aventureros españoles denominaron este sitio Valle del Paraíso, designación que su aspecto presente, por lo menos, de ninguna manera justifica", 16. 
otro marino británico que estuvo en la ciudad al poco tiempo ${ }^{8}$. En similares términos de decepción se expresa John Miers quien permaneció en nuestra región por varios años y luego de no poder vencer la burocracia criolla debió abandonar el país sin poder instalar una importante empresa minera. Miers manifestó su desengaño respecto a las cualidades de la ciudad por cuanto había leído que esta poseía hermosos árboles y edificios con deliciosos paseos para el visitante, en cambio, según su parecer, Valparaíso era "lo más triste que se puede concebir. En poco tiempo el lugar se vuelve casi intolerable, puesto que, independientemente de la carencia de sociedad, no existen entretenciones públicas, ni teatro, ni ninguna biblioteca pública donde se pueda ir a leer revistas o diarios, ni siquiera hay un lugar para ir a pasear, excepto los cansadores y empinados cerros, o las calles angostas y sucias donde a consecuencia de los frecuentes y violentos vientos sur, se levanta polvo y arena en forma de nubes, para gran molestia de los transeúntes"9.

Entre los espectáculos que presenció Basil Hall estuvieron las corridas de toros que describe como pueriles, ya que "los animales nunca se mataban, sino que solamente eran atormentados por los jinetes que los aguijoneaban con lanzas toscas, o distraídos por hombres a pie que los capeaban y que cuando los toros se enfurecían, se escapaban saltando la barrera y se refugiaban en las ramadas"10. En cuanto a la sociedad porteña de la época, hace notar el deficiente estado de la educación que caracterizaba especialmente a los hombres, ya que "el refinamiento, no obstante, estaba todo en el bello sexo; en conocimiento del mundo, sano juicio y en todo lo relativo a modales eran manifiestamente superiores a los hombres" ${ }^{11}$. Señala también la positiva disposición hacia los extranjeros mostrándose corteses e indulgentes ante sus dificultades con el idioma castellano.

Poco tiempo después estuvo en Valparaíso Alejandro Caldcleugh, quien llegó desde Santiago y su descripción de la primera mirada sobre la ciudad es totalmente diferente de la entregada por sus compatriotas anteriormente citados. La visión del mar y los buques ubicados en su bahía atrajeron su atención provocándole una muy positiva impresión ${ }^{12}$. Su estadía fue breve y sus notas son más bien descriptivas. Sobre la ciudad hace notar el pobre aspecto de las casas señalando que la edificación de nuevos almacenes revelaba que el comercio estaba adquiriendo "gran giro"13.

8 Richard Longeville Lowell, Campañas y Cruceros en el Océano Pacífico, Editorial Francisco de Aguirre, Santiago 1968, 37, señala: "La vista que se ofrece al entrar a la bahía de Valparaíso no corresponde de modo alguno al nombre de la ciudad. Los altos cerros de que está rodeada de los costados sud y del oriente, son casi estériles y parecen inadecuados para el cultivo, sin producir otra cosa que un pasto obscuro y espinoso, al través del cual se diseñan sendas de color rojizo brillante...".

9 John Miers, Travels in Chile and La Plata, traducción de Marina Coloma Gómez, memoria para optar al título de profesora de Estado Universidad de Chile, Valparaíso 1960, 144.

10 Basilio Hall, op. cit, 19.

11 Ibid, 27.

12 Alejandro Caldcleugh, "Viaje a Chile en 1819, 1920 y 1921", en: Samuel Haigh, Alejandro Caldcleugh y Max Radiguet, Viajeros en Chile 1817-1847, Editorial del Pacífico, Santiago 1955. Su descripción de Valparaíso fue la siguiente: "Se presentó a mi vista un panorama tan bello e interesante que dejó hondas huellas en mi memoria: el sol iba trasponiendo magníficamente las gruesas capas de una densa neblina, lo que permitía ver nítidamente, casi a mis pies, la bahía de Valparaíso con todos los buques al ancla en el puerto", 188 .

13 Ibidem, 189. 
En cuanto a la presencia de británicos durante los primeros años, los viajeros nos dejan también referencias interesantes, ya que, si bien no son muchos al comienzo, rápidamente comenzaron a hacerse notar. El ya mencionado Richard L. Vowell, que estuvo en nuestro puerto en varias ocasiones durante la década de 1820, nos cuenta de la concentración británica en el Cerro Alegre, en donde habría sido su primer habitante un comerciante inglés de apellido Bateman quien fue asesinado por sus peones. Hace notar también la presencia en dicho barrio del vicecónsul inglés $\mathrm{Mr}$. White y de un capitán Ross que regentaba una casa de huéspedes en donde además se podía jugar billar ${ }^{14}$. Vowell, quien se desempeñó como oficial de nuestra marina de guerra al mando de Cochranne, fue uno de los testigos de lo acontecido para el terremoto de 1822 y narra con cierta detención los acontecimientos de dicha ocasión. En cuanto a los ingleses hace notar que por no ser católicos, al comienzo, no les estaba permitido enterrar a sus muertos en tierra consagrada (cementerios, iglesias), que eran de propiedad de la Iglesia Católica, por lo cual durante algunos años ocupaban para tales funciones el fuerte San Antonio u otros lugares cerrados, hasta que O’Higgins les autorizó a tener su propio cementerio ubicado en el lugar que hoy conocemos como Cementerio de Disidentes. Respecto a los frecuentes temporales, hace notar las dificultades que tiene la bahía sobre todo en invierno y narra el caso específico de uno que ocurrió en 1923 que ocasionó la pérdida de 18 naves. En esa ocasión, se produjo un hecho curioso que involucró a una madre inglesa y su pequeño hijo quienes fueron rescatados por peones desde la orilla a través de su destreza en el uso del lazo. A partir de este acontecimiento, narra cómo la población se apoderaba de las mercaderías que transportaban los buques que naufragaban y que pronto se expendían en diferentes lugares de la ciudad ${ }^{15}$.

Para 1822 destaca también la presencia de María Graham cuya difundida obra nos dejó valiosos testimonios de la sociedad de la época como del ámbito político de ese interesante período en que O'Higgins y Cochrane se involucraron en la independencia del Perú. Su percepción, en cuanto a la presencia británica, aparece un poco exagerada cuando afirma que "en todas las calles se ven carteles de sastres, zapateros, talabarteros y posaderos ingleses; y la preponderancia del idioma inglés sobre todas las demás lenguas que se hablan en la calle, lo haría a uno creerse en una ciudad de la costa inglesa"16. Al respecto, John Miers, hacía notar que los datos que se le entregaron sobre la población de Valparaíso eran muy poco confiables por cuanto se decía que la ciudad tenía 15.000 habitantes de los cuales 3.000 eran ingleses. Sin embargo, él consideraba que en el mejor de los casos la población era de 6.000 habitantes entre los cuales se podrían encontrar no más de 400 ingleses ${ }^{17}$. Reconoce sí que de los barcos en la bahía dos tercios son de origen británico y que el comercio extranjero está mayoritariamente en manos de sus compatriotas $^{18}$. Desconocemos la fuente consultada por Miers, pero efectivamente

14 Richard L. Vowell, op. cit., 41.

15 Ibidem, 47-48.

16 María Graham, Diario de mi Residencia en Chile, 1822, Editorial del Pacífico, Santiago, 40.

17 John Miers, Travels in Chile and La Plata, traducción de Marina Coloma Gómez, memoria para optar al título de profesora de Estado Universidad de Chile, Valparaíso 1960, 142.

18 Ibidem, 143. 
esas cifras se manejaban por algunos viajeros ingleses, como es el caso de William Bennet Stevenson, que recorrió nuestras costas desde comienzos del siglo XIX, y afirmó que para 1822 la ciudad tenía 15.000 habitantes de los cuales 3.000 eran extranjeros ${ }^{19}$. En similares términos, el viajero francés Gabriel Lafond de Lurcy, que estuvo en Valparaíso en 1822, sostenía que la ciudad tenía entre 15000 y 17.000 habitantes, entre los cuales figuraban 3.000 extranjeros, siendo las tres cuartas partes de ellos norteamericanos o ingleses ${ }^{20}$.

Entre las contribuciones, que advierte María Graham, de parte de los ingleses hace notar el establecimientos de carnicerías ya que tales establecimientos regentados por nativos en virtud del burdo método de cortar las carnes "ofendía la vista y el gusto de un inglés". Graham señala además la enorme cantidad de pianos ingleses existentes en la ciudad, en donde eran un instrumento común en el uso de los jóvenes, que lo interpretaban generalmente de oído ${ }^{21}$. Robert Proctor, que nos visitó en 1823, se refiere a sus compatriotas en términos bastante despectivos diciendo que la ciudad está llena de ingleses, muchos de ínfima condición y de pésimo carácter; operan de corredores, contrabandistas, etc., y aferran al pobre extranjero que llega con consignación de mercaderías, dejándole generalmente arrepentimiento por su credulidad". En verdad, los juicios de Proctor se caracterizaron por su carácter acervo por cuanto tampoco nuestra sociedad quedó bien parada ya que, según su opinión, los naturales chilenos son considerados de los más sanguinarios e incivilizados de todos los hispanoamericanos y aunque muestran mucha cortesía exterior, sacan cuchillo a la menor provocación" 22 . Por su parte, el reverendo Hugo S. Salvin, que estuvo en Valparaíso en 1824, coincidía con Proctor cuando hacía notar que según información que le entregaron los propios ingleses, el carácter moral de los porteños hallábase en un estado muy lamentable de degradación; y respecto a sus compatriotas lamentaba que muchos desertores de buques ingleses se habían transformado en pulperos ${ }^{23}$.

En cuanto a la ciudad, María Graham deja en claro sus limitaciones reconociendo que es uno de los más grandes puertos del continente, pero que en realidad "es poco más, en apariencia, que cualquier pueblo inglés de pescadores" 24 . También se muestra muy crítica en cuanto a las incomodidades que se advierten en las condiciones de vida y ante lo cual afirma que "se encuentra menos bienestar en un palacio de Chile que en la choza de un labrador de Escocia"25.

Tal como lo refieren numerosos relatos de marinos británicos, como también otras fuentes de la época, la presencia de los barcos ingleses, como el rápido estable-

19 William Bennet Stevenson, Memorias de William Bennet Stevenson sobre las Campañas de San Martín y Cochrane en el Perú, Editorial América, Madrid s/f, 72.

20 Gabriel Lafond de Lurcy, Viaje a Chile, Editorial Universitaria, Santiago 1970, 24.

21 M Graham, op. cit. 40.

22 Robert Proctor, Narraciones del Viaje por la cordillera de los Andes y residencia en Lima y otras partes del Perú en los años 1823 y 1824, La Cultura Argentina, Buenos Aires 1920, 77.

23 Hugo S. Salvin, "Diario escrito a bordo del buque de Su Magestad 'Cambridge' desde enero de 1824 hasta mayo de 1827”, en Revista Chilena de Historia y Geografía, Vol. 36, Santiago 1919.

24 M. Graham, op. cit, 71.

25 Ibidem, 44. 
cimiento de casas comerciales británicas en Valparaíso, testimoniaron la importancia que poseía Inglaterra en la economía internacional. A partir de la década de 1820 comenzaron a surgir empresas como Antony Gibbs and Sons, Limited; Williamson Balfour Company, Limited; Duncan Fox and Company, Limited; Frederick Huth and Company $^{26}$. A partir de 1818 la preeminencia británica en el comercio mayorista es palmaria, desplazando totalmente a los españoles (ver cuadro $\mathrm{N}^{\circ} 2$ ). Algunas de estas casas comerciales prolongaron su presencia hasta el siglo $\mathrm{XX}$.

\section{CUADRO No 2}

\section{NACIONALIDAD DE LOS 40 COMERCIANTES MÁS IMPORTANTES EN CHILE SEGÚN MOVIMIENTO ADUANERO DE VALPARAÍSO Y SANTIAGO 1808-1838}

\begin{tabular}{lccc}
\hline Año & $1808-1818$ & $1818-1828$ & $1828-1838$ \\
\hline País & 7 & 11 & 7 \\
Chile & 28 & 3 & 1 \\
España & - & 16 & 12 \\
Gran Bretaña & - & 7 & 2 \\
Argentina & - & 2 & 2 \\
U.S.A. & 5 & 1 & 11 \\
No identif. & & & \\
\hline
\end{tabular}

Fuente: John Rector Merchants, Trade and Commercial Policy in Chile: 1810-1840 (Unpublished Ph.D dissertation)

\section{DESARROLLO COMERCIAL DURANTE EL SIGLO XX}

Antony Gibbs and Sons fue una de las primeras y eventualmente una de las más grandes casas comerciales operando en Chile. Se abrió en Valparaíso por John Moers desde Perú en 1926. El mismo año se abrió una sucursal en Santiago pero cerró en 1835 para reabrir solo en $1909^{27}$. Posteriormente se ampliaron también a Iquique, Antofagasta, Concepción Talcahuano, Mejillones, Temuco y otras ciudades del país. A partir de 1865 se involucraron en la producción de salitre y luego del triunfo de Chile, en la Guerra del Pacífico contra Perú y Bolivia, cerraron en Perú y abrieron oficina en Iquique en 1881. Desde comienzos del siglo XX comenzó a operar como Gibbs y Cía manteniendo la firma como el negocio más importante la comercialización del salitre y actuando también como agentes y banqueros de las compañías

26 Cavieres, Eduardo. Comercio Chileno y Comerciantes Ingleses 1810-1880: Un Ciclo de Historia Económica, Serie Monografías Históricas $\mathrm{N}^{\circ} 2$, Instituto de Historia Universidad Católica de Valparaíso, 111.

27 Zimmerman, Daniel. British Influence in the Modernization of Chile, 1860-1914, Dissertation Thesis, The University of Mexico, Ph D. 1977, 44. 
salitreras inglesas y chilenas. Como derechos de exportación, en 1913 esta casa pagó al gobierno de Chile la suma de 700.000 libras esterlinas. En cuanto a importaciones traían al país carbón, hierro, artículos de acero, maquinaria agrícola y de otras clases, sacos, automóviles, explosivos y mercancía en general. En las exportaciones se incluían trigo, cebada, avena y otros productos agrícolas. En estos negocios actuaba también como banqueros de los agricultores, facilitándoles dinero y maquinarias a cambio de sus productos. Es decir, la empresa compraba las producciones "en verde" obteniendo un margen muy positivo a su favor. Hasta el inicio de la I Guerra Mundial la empresa mantuvo una posición expectante y de primer nivel en la actividad comercial-financiera del país. Además de las actividades señaladas tenía a su cargo las agencias de la New York \& America Steamship Co., línea que se había fundado para facilitar el comercio entre Chile y los Estados Unidos. A fin de realizar las actividades de embarque poseía una flotilla de lanchas y un remolcador. Representaban también a compañías inglesas de seguros como la Phoenic Fire, la Yorkshire Fire y la Norwick Union Life Insurance. Entre las múltiples representaciones de empresas manufactureras europeas y norteamericanas podemos mencionar las siguientes: Asiatic Petroleum Co. Ltd., bujías y parafina; Mirrlees, Bickerton \& Day, máquinas Diesel; Curtis's \& Harvey Ltd., explosivos, Columbia Refining Co., aceites y grasas; Wm. Bennet \& Son, mechas para minas; D. Anderson \& Son, pintura anticorrosiva; Storry Smithson \& Co. Ltd., pinturas al óleo y al agua; H. Wilson Young \& Co., pavimentos; J Dewar \& Son, wisky; Buffalo Pitts Manufacturing Co., trilladoras y otras máquinas; Champion Harvester Co., máquinas segadoras; Ford Motor Co. automóviles ${ }^{28}$.

Gibbs y Co. por otro lado realizaba excelentes negocios desde Chile como por ejemplo la compra al Gobierno de Chile de los acorazados Libertad y Constitución que luego vendió a Inglaterra. Las sucursales del norte, específicamente Antofagasta, Mejillones e Iquique se concentraron en la actividad minera para lo cual contaban con una importante infraestructura en almacenes, instalaciones portuarias, flotillas de lanchones y remolcadores. Su involucramiento en la actividad salitrera les llevó a realizar importante inversiones, para lo cual contaban con un destacado equipo de profesionales y técnicos compuesto de ingenieros, químicos que estudiaban e investigaban los yacimientos. En todo caso, también participaban en la comercialización y extracción de cobre y estaño. En el ámbito agrícola, centraban su actividad en la región de Concepción poniendo a disposición de los agricultores maquinaria especializada y capital. Entre las propiedades que allí poseían se encontraba un importante molino en Tomé con maquinaria moderna y excelentes instalaciones para transporte de insumos y producción. Una vez que consolidaron su posición en Concepción ampliaron su gestión hasta la región de La Araucanía estableciéndose en Temuco en donde también instalaron un molino ${ }^{29}$.

Las efectos derivados de la I Guerra Mundial afectaron fuertemente las actividades en el norte de Chile como también ocurrió con el resto de los negocios luego

28 Reginald Lloyd, Impresiones de la República de Chile en el Siglo XX, Jas Truscott and Son Ltd. Artistas Impresores, Londres 1915, 338.

29 Ibidem, 340. 
de la crisis provocada en 1929. Esto significó que las actividades se redujeron de tal modo que para 1932 encontramos que Gibbs se asocia con Williamson Balfour, declarando cada empresa una participación de $\$ 500.000$ para operar como representantes y agentes con sucursales en Arica, Antofagasta y Tocopilla ${ }^{30}$. Aunque en un nivel menor al que mostró a comienzos del siglo se mantuvo operando en Chile por el resto del período que nos interesa.

Otra firma comercial importante fue Balfour, Williamson and Co. que comenzó a operar, a mediados del siglo XIX, fundamentalmente como importadora de productos europeos. Pronto advirtieron lo beneficioso que podía resultar el exportar minerales y es así como para 1859 invertían sobre 100.000 libras esterlinas en la exportación de cobre y salitre. Posteriormente, a sugerencias de Stephen Williamson se involucraron en la compra de acciones ferroviarias en donde muy pronto actuaron como agentes y financistas. A fines del siglo XIX, conjuntamente con Gibbs y Duncan Fox, eran los mayores exportadores de trigo chileno. Hacia 1910 el $70 \%$ de las exportaciones de trigo se dirigían a Gran Bretaña. Estas actividades les llevaron a levantar un molino en Concepción. Desde Valparaíso y bajo su directa tuición, en 1882 se abrió una oficina en Iquique para dedicarla a la comercialización salitrera, la que luego también se dedicó a la importación de carbón, herramientas y bolsas para el transporte de salitre ${ }^{31}$.

Posteriormente, amplió su gestión en la agricultura comprando otros molinos, ampliando el nivel de exportaciones de ese sector y abriendo sucursales en diversas ciudades vinculadas al quehacer agrícola, como fue el caso en San Felipe, Chillán, Los Ángeles, Temuco, Valdivia y Osorno ${ }^{32}$.

A la manera de las firmas mencionadas hubo muchas otras importadoras-exportadoras que cubrieron diversos espectros de la economía nacional. Algunas tuvieron una vida efímera pero hubo otras que se mantuvieron permaneciendo algunas hasta la llegada de Allende al poder. Es el caso de Weir Scott y Cía. Esta empresa comenzó sus actividades en Valparaíso en 1856 con importaciones de licores y abarrotes. Pronto instalaron sucursales en otras ciudades como Santiago, Antofagasta, Concepción. Durante el siglo XX fueron ampliando sus actividades involucrándose incluso en el sector industrial ya que desde comienzos del siglo XX poseyó una moderna planta de leche condensada en Graneros que abastecía a todo el país. Agréguese a esto que Andrés Scott, principal socio de la firma, poseía un tercio de las acciones de industrial McKay de Santiago ${ }^{33}$. Luego asumió la propiedad del agua mineral "Jahuel". Es así entonces que a mediados de siglo XX poseían variadas representaciones de productos extranjeros, actividades navieras y participación en empresas nacionales como fábricas y elaboradoras de agua mineral y bebidas de fantasía. Hacia 1955 tenían más de 100 operarios y un equipo directivo en que figuraban como seis británicos ${ }^{34}$.

\footnotetext{
30 Archivo Registro del Comercio de Valparaíso (en adelante RCV), año 1932, fs 421 y 473.

31 Zimmerman, Daniel, op. cit. 54.

32 Empresa Editorial Cronos, Chile en Sevilla, Santiago 1929, CLIII.

33 Couyoumdjian, Ricardo, "El Alto Comercio de Valparaíso y las Grandes Casas Extranjeras, 1880-1930. Una Aproximación", Historia, Vol. 33. 2000, 84.

34 Reginald Lloyd, op . cit. 376; entrevista al Sr. Kurt Levhison, ex funcionario de la empresa.
} 
También encontramos casos destacados de firmas británicas que aún se mantienen operativas, aunque en ningún caso con la relevancia que tuvieron en la dorada época de comienzos de siglo, como es el caso de la Agencia Naviera de George C. Kenrich y Cía., que se fundó en enero de 1901 dedicada a la importación de carbón, coke y negocios marítimos. Posteriormente se amplió a otros rubros anexos como por ejemplo el establecimiento de fábricas de gas en Talcahuano, Coquimbo y Copiapó. También fue propietaria de la Fábrica de Electricidad y Fuerza Motriz de Talcahuano. En Valparaíso se desarrolló una creciente infraestructura portuaria orientada a satisfacer la creciente demanda. A los grandes depósitos para almacenar combustibles y mercaderías se agregaban remolcadores, grúas, lanchas a vapor, depósitos flotantes y diversos medios que facilitaban la carga y descarga de mercadería de tal modo que desde los barcos los productos eran trasladados al ferrocarril para ser distribuidos a través del país. En los servicios navieros además de remolcar las naves y efectuar los trámites correspondientes para su movimiento marítimo, les suministraba agua potable y lastre. Tuvo también una línea regular de vapores entre Newcastle y Valparaíso que se dedicaba preferentemente al transporte de carga ${ }^{35}$. Actualmente aún existe la firma, pero como una pequeña oficina que se mantiene en el rubro naviero. El establecimiento permanece en manos de la familia y sus miembros han tenido permanentemente una destacada participación dentro de le colectividad. Entre otros cargos han ocupado el de Cónsul Honorario de Gran Bretaña.

Vinculado a todas las actividades económicas de la colectividad británica y en general ocupando una posición destacada en la economía nacional surgen dos instituciones bancarias cuya presencia en otros puertos y capitales de América revela la relevancia de la participación británica en el desarrollo económico latinoamericano de la época. El Banco de Londres Río de La Plata fue fundado en Londres en 1862 llegando a tener más de 2.000 sucursales en todo el mundo.

La otra institución bancaria era el Banco Anglo-Sudamericano Ltd. Esta institución nació más ligada al quehacer económico nacional ya que se creó en 1889 como Banco de Tarapacá \& Londres a fin de participar en las negociaciones salitreras entre Chile y Gran Bretaña, especialmente las dirigidas por su fundador John North. Comenzó con sucursales en Valparaíso, Iquique y Pisagua pero luego de diez años de estar operando en nuestro país se fusionó con el Banco Anglo Argentino constituyendo así, el año 1901, el Banco Anglo Sudamericano. Posteriormente abrieron sucursales en Nueva York, París y otras ciudades europeas, entre ellas, a partir de 1917, seis ciudades españolas. Esta circunstancia determinaba que este fuera el banco oficial para las transacciones que se desarrollaban entre el gobierno español con la respectiva embajada y consulados que representaban a España en Chile. El crecimiento paulatino de este banco en América Latina se tradujo en la compra de diversos bancos que operaban en el continente. Para 1912 adquirió los negocios del Banco de Londres, México y Sudamérica y en 1919 la mayor parte de las acciones del Commercial Bank of Spanish America Ltd. Un año más tarde se hizo cargo del British Bank of South America. En 1914 las inversiones del banco

35 Ibidem, 355 . 
en Chile se concentraban especialmente en compañías salitreras y eran de 8 millones de dólares ${ }^{36}$. Para 1922 el fondo de reservas ascendía a la suma de 3.859,000 libras esterlinas, mientras que el capital era de 8.729,040 libras esterlinas de las cuales 4.364,520 libras esterlinas estaban totalmente pagadas ${ }^{37}$.

El imponente edificio construido para este banco en Valparaíso aún se mantiene y es sin duda un palmario testimonio del poderío que tuvo la institución dentro del movimiento financiero de la ciudad en sus vínculos comerciales internacionales. Es así como fuera de las habituales operaciones de cuentas y ahorros en distintas monedas tenía un significativo movimiento en la negociación de letras documentarias contra embarques, traspaso de fondos y emisión de cartas de crédito sobre diversas plazas bancarias en el mundo ${ }^{38}$.

De acuerdo a las estadísticas oficiales de Chile los bancos británicos, en 1914, poseían el $15 \%$ del total de activos bancarios, lo que correspondía al $31 \%$ de los activos de los bancos extranjeros establecidos en el país. Para ese mismo año, los bancos británicos tenían el 25\% del total de los depósitos bancarios y el $77 \%$ que poseían los bancos extranjeros ${ }^{39}$.

Cabe recordar que además muchas casas importadoras operaban también como instituciones financieras. Fue el caso de las mencionadas Gibbs y Cía. y Williamsom Balfour las que operaban en el comercio internacional a través de varios tipos de créditos internacionales especialmente para el caso de libras esterlinas. Entre sus servicios estaba el asegurar la obtención de préstamos de parte de prestamistas internacionales como era por ejemplo en el caso del propio gobierno de Chile. Proporcionaban información crediticia acerca de las grandes casas-bancos establecidas en Londres como las pertenecientes a Rothschild, Morgan o Baring. Ocasionalmente también realizaban préstamos a municipalidades o empresas industriales pero en todo caso el principal interés para ellos estaba en el comercio internacional ${ }^{40}$.

Fue habitual también que estas casas comerciales poseyeran acciones en bancos locales. Para 1890 Gibbs poseía 24 acciones en el Banco Nacional de Chile por un valor de 24.000 pesos. Al mismo tiempo poseía acciones en el Banco de Valparaíso y bonos del Banco Hipotecario de Chile ${ }^{41}$.

Muchas obras municipales o en beneficio de las ciudades se realizaban a través de empréstitos conseguidos en Londres a través de bancos o casas comerciales. En el caso de Valparaíso podemos mencionar el crédito concedido a la empresa de agua potable en 1912 por la suma de 250.000 libras esterlinas por J. Henry Schroeders \& Company of London. En 1913, The London City and Midland Bank Ltd., prestó a la Municipalidad de Viña del Mar 200.000 libras esterlinas. Para la reconstrucción de Valparaíso, luego del terremoto de 1906, el gobierno chileno, en

36 Zimmerman, Daniel, op. cit. 158.

37 Escobar, Aníbal. Gran Bretaña en Chile 1923, Imprenta y Litografía La Ilustración, Santiago 1924,226

38 Escobar, Aníbal, El Príncipe de Gales en Chile. Homenaje de la Colonia Británica a SAR, Santiago de Chile 1925-1926, Imprenta y Litografía La Ilustración, Santiago 1926, 138.

39 Chile. Anuario Estadístico 1914, Vol. IX, 144-145.

40 Zimmerman, Daniel, op. cit. 139.

41 Ibidem, 147. 
1909, obtuvo de parte de Rothschild \& Son, 3.000.000 de libras esterlinas con un interés del 5\%. Dos años más tarde obtenía un nuevo préstamo de los mismos financistas por la suma de 5.000.000 de libras esterlinas a fin de realizar diversas obras portuarias en Valparaíso y efectuar adquisiciones navales ${ }^{42}$.

La numerosa colectividad británica concentrada fundamentalmente en el comercio exterior se agrupó en la Cámara Británica de Comercio que se fundó en 1917 con la participación de aproximadamente 30 empresas, entre las cuales figuraban los bancos y casas comerciales reseñadas, conjuntamente con otras importantes firmas tradicionales del puerto como Allardice \& Co; Betteley \& Co. Ltd.; Bushell \& Co.; Duncan Fox \& Co.; Buchanan Jones \& Co.; Lazonby \& Co, etc. Para 1927 la institución tenía registrados a más de 200 socios y tenía sucursales en Iquique, Antofagasta, Concepción y Valdivia. Para ese año dirigían la institución W. O. Simon como presidente y A. R. Balfour como vicepresidente. Entre los consejeros aparecían David Blair, A. P. Colquhoun, F Evans, A. Foden, C. B. D. Fox, E. W. Gubbins, W. J. Hardy, A. L. S. Jackson, Thos Linley, W. C Maycock, H. Nation, H. V. Prentice, Geo Proud, J. R. Ross, F. C. Ross-Brown, W. F. Stanton, C. K. Walbaum ${ }^{43}$.

En realidad la creación de esta institución se vincula con la I Guerra Mundial ya que hasta la fecha de su aparición los comerciantes se reunían en la Cámara de Comercio de Valparaíso, organismo que no tenía características étnicas y por el contrario agrupaba en forma plural al gran comercio local con una importante participación de los comerciantes alemanes. Fue Maclean, el cónsul británico, quien se preocupó de llevar a cabo el proyecto de la Cámara étnica con cierta dificultad ya que en un principio no fue apoyado por los comerciantes. El propósito de marginarse de la Cámara de Valparaíso era aplicar las restricciones a los alemanes a partir de las denominadas "listas negras". Para los comerciantes ingleses no resultaba muy atractivo desde el punto de vista comercial el restringir sus actividades, sobre todo cuando había muchos que no solo comerciaban o representaban a firmas alemanas, sino que además tenían algunos socios de esa nacionalidad. Por su parte, el cónsul, sostenía que la reticencia de los ejecutivos británicos se debía a "los celos y competencia comercial entre las firmas británicas" 44 . La perseverancia del diplomático dio sus frutos en julio de 1917 cuando finalmente reúne un grupo de comerciantes ingleses que pronto fue creciendo. A fines del primer año de existencia la Cámara tenía 234 miembros a lo largo del país ${ }^{45}$.

La variedad de rubros que cubrían los comerciantes británicos era muy extensa y podemos mencionar entre ellos, a manera de muestra, algunos establecimientos, especialmente aquellos que se mantuvieron a través del período correspondiente a la primera mitad del siglo XX.

42 Ibidem, 65-66.

43 El Mercurio de Valparaíso, 12 de septiembre de 1927.

44 Couyoumdjiam, J. Ricardo, Chile y Gran Bretaña durante la I Guerra Mundial y la Postguerra, 1914-1921, Editorial Andrés Bello, Santiago 1986, 146.

45 Ibidem. 
Allardice y Cía. se estableció en Chile en 1876. Operaban como agentes de compañías de seguros contra incendios y riesgos marítimos, explosivos, fábricas de tejidos ${ }^{46}$. Betteley y Cía. fue fundada a fines del siglo XIX por Alfredo Betteley. Inició sus actividades como importador de artículos de mercería y té. Luego del fallecimiento del fundador se sustituyeron los artículos de mercería por artículos de fantasía para regalos, loza y cristalería. Quienes asumieron el control de la empresa fueron sus hijos Claudio y Eduardo Betteley. Luego de 1915, como consecuencia de la guerra, se dedicó a la representación de firmas extranjeras, especialmente japonesas. Ante las dificultades para traer el té empaquetado desde Inglaterra se tomó la decisión de hacerlo en Chile. Luego de finalizada la guerra se terminaron las representaciones y el establecimiento se concentró en el negocio del té y ampliaron su acción abriendo una sucursal en Santiago. Para 1925 trabajan en el plantel cerca de 200 personas como empaquetadores del té "Santa Filomena". La mayoría de estos empaquetadores eran niñas menores de edad. Para ese período se empaquetaban anualmente 50.000.000 de paquetes y reconocían un capital de $\$ 1.500 .000 \operatorname{pesos}^{47}$. Entre los mecanismos novedosos para atraer a sus clientes establecieron un sistema de cupones impresos en las etiquetas que el público podía canjear por prácticos regalos de uso casero. En 1933 la empresa se registró como sociedad, por un período de nueve años, con un capital de $\$ 2.300 .000$ con la participación de cuatro socios: Claudio Betteley Melosi que aportó \$1.800.000, Eduardo Betteley Melosi con $\$ 300.000$, Alfredo Betteley Mahan con $\$ 100.000$ y Enrique Stuven con $\$ 100.000^{48}$. El edificio se ubicaba en Avenida Francia. Esta empresa se mantuvo operativa hasta la segunda mitad del siglo XX y miembros de la familia Betteley aún residen en Viña del Mar.

Vinculadas a la comercialización del té podemos también mencionar al emporio perteneciente a Alejandro McGaw, ubicado en calle Esmeralda, fundado en 1878 por Roberto Baird y que vendió en 1893 a McGaw. Proveía del reconocido té "Imán", loza inglesa, decoraciones para mesas y otros diversos artículos como mantequilla fresca esterilizada. Tenía un servicio de entrega a domicilio con sus propios camiones ${ }^{49}$. En 1922 aparece, como parte de esta cadena de firmas relacionadas con este producto de tan característico consumo británico, The English Tea Room como iniciativa de C. J. G Vogel y Helen Vogel. Este salón de té estaba ubicado en calle Prat y se ofrecía especialmente como un servicio para los hombres de negocio. Se ofrecía entre sus ventajas el no poseer música "de esta manera, el hombre de negocios que acude a él, aparte de un excelente servicio de té, café o chocolate cuenta con la seguridad de poder tratar sus asuntos de la manera más tranquila posible" 50 . EN 1917 aparece en Valparaíso la firma W.H. \& F. J. Horniman, Ltd. que decidió instalarse en Chile para empaquetar su té, luego de las dificultades que le planteaba la guerra en sus sucursales europeas. Esta empresa

\footnotetext{
46 Ibidem.

47 Escobar Aníbal, El Príncipe de Gales... 163.

48 RCV, 1933,Vol. 59, foj. 404-466.

49 Escobar, Aníbal, El Príncipe de Gales... 169

50 Ibidem, ...253.
} 
ocupaba a 400 obreros. Esta casa había sido fundada en 1826 en Londres por el cuáquero John Horniman ${ }^{51}$.

Duncan Fox \& Co. se fundó en Liverpool en 1864. En Valparaíso apareció primero como Sawers, Duncan \& Co. y en 1876 adoptó el nombre de Duncan Fox y Cía. Sus fundadores fueron David Duncan y Henry Frederick Fox. Duncan nunca vino a Chile, en cambio Fox vivió en la ciudad por varios años y previo a su sociedad con Duncan fue socio de Ravenscroft, Fox \& Co. Regresó posteriormente a Liverpool en donde falleció en 1911. Hacia 1915 los socios de la empresa eran Thomas Woodsend, A. C. Mitchell, A. L. Duncan, F. H. Fox, P. H. McClella, J. G. Reid, A. H. Gold Finsh y J. L. Davies. En un principio la firma operaba solo en Valparaíso y Liverpool, pero en 1876 abrió una sucursal en Lima y en 1879 en Manchester a fin de adquirir allí las telas. En Chile se abrieron sucursales en Concepción (1878), Santiago (1900) y Antofagasta (1906) desde donde se abrieron posteriormente las sucursales de La Paz y Oruro. Asimismo se abrió una sucursal en Londres en 1910. La firma operaba fundamentalmente como exportadora e importadora entre Chile y Gran Bretaña para lo cual poseía sus propios buques, entre otros, Foxglove, Gayton, Hall. Aunque la principal mercadería que traían eran telas también encontramos una amplia diversidad de productos ingleses como sacos, arroz, azúcar, hierro galvanizado, cemento, lonas para barcos, hilo para coser, etc. Hubo también un período, 1903-1910, en que fueron los únicos en importar petróleo, reemplazando así al carbón. Posteriormente mantuvieron el control mayoritario de la comercialización de ese combustible. En el ámbito de las exportaciones representan a importantes firmas británicas establecidas en el país de tipo ganadero, agrícola e industrial. Al mismo tiempo fueron agentes de las líneas de vapores Braun y Blanchard entre Valparaíso y Punta Arenas perteneciente a capitales británicos ${ }^{52}$. Esta empresa corresponde a un prototipo de establecimiento extranjero que opera desde el exterior enviando funcionarios como representantes. $\mathrm{Su}$ actividad es estrictamente comercial y responde a las características propias de un sistema colonialista. En 1929 aparecían como sus representantes para Chile James Mc Duwall, James Mc Morries, Kenneth Bisset y Eric E. Davies ${ }^{53}$. Corresponde también a las empresas de mayor estabilidad y permanencia en el país.

Similares características a la de Duncan Fox, en su forma de operar, tuvo la firma Huth y Cía que fue una de las primeras en establecerse en Valparaíso (1824) por iniciativa de Frederick Huth conjuntamente con otros comerciantes y banqueros londinenses. Esta firma operó bajo la denominación de Frederick Huth, Grüning y Cía hasta 1878 cuando adquirió el nombre con que operó a lo largo del siglo XX. Además de ejercer funciones bancarias, exportaban productos mineros e importaban géneros de todo tipo. Posteriormente se especializaron en instalaciones eléctricas como representantes de la General Electric Co. de Londres. Representaron también a diversas compañías de $\operatorname{seguros}^{54}$. Tuvo sucursales en diversas ciuda-

\footnotetext{
51 “La Casa W. H. \& F. J. Horniman”, Ltd., en Zig-Zag, N 843.

52 Lloyd, Reginald, op. cit. 354

53 RCV, 1929, foj. 436.

54 Lloyd, Reginald, op . cit. 361
} 
des del país como Santiago, Concepción y Coquimbo como también diversas agencias en ciudades menores. En 1925 representaban a la firma en Valparaíso Carlos Walbaum, Charles E. Sutton y Henry. N. Phillips ${ }^{55}$. Walbaum aunque era inglés, era hijo de alemanes por lo cual durante la I Guerra fue llamado por la firma, en 1916, para que regresara a Inglaterra. En esa ocasión otro de los socios que era alemán fue marginado de la firma ${ }^{56}$. En 1931 la firma aparece constituida por cuatro socios: Frederick Huth que aporta 7.500 libras esterlinas; Charles Evans Sutton con una participación pecuniaria de 2.250 libras esterlinas; Harry Pommeroy con 1250 libras esterlinas y Henry Nelson Phillips con 250.000 libras esterlinas. Huth y Pommeroy residían en Londres, mientras Sutton lo hacía en Valparaíso y Phillips en Concepción ${ }^{57}$. Dos años mas tarde desaparece de la sociedad Pommeroy y se integra Alberto Bernardo Sutton ${ }^{58}$.

The Gourock Ropework Export Co. Ltd. se creó en Gourock, Escocia, en 1736, estableciendo una agencia en Valparaíso en 1902. Eran fabricantes de cordeles de todas clases, lonas, lienzos, tiendas de campaña, etc. Proveen a varias dependencias gubernamentales (Correos, Ferrocarriles) como también de las Fuerzas Armadas ${ }^{59}$. Para la década de 1920 desaparecen pistas sobre esta empresa por lo cual suponemos que luego de la guerra no pudo continuar con sus actividades que eran exclusivamente de importación. Este es un caso que se repitió con varias otras empresas importantes de comienzo de siglo que luego desaparecieron provocando una importante disminución de la presencia británica en la actividad económica de Chile.

Efectivamente, luego de la crisis de 1929, se produjo un muy negativo impacto en el comercio mayorista internacional de Valparaíso. "Si bien la gran mayoría de estas casas comerciales logró superar la crisis y adaptarse a las nuevas circunstancias, ellas perdieron importancia en relación al conjunto de la economía nacional. El control de divisas impuesto por la autoridad monetaria en 1931, unido a las restricciones en las transacciones a plazo de letras de cambio, que eran las más, afectó con especial fuerza a la bolsa porteña que fue perdiendo importancia frente a su congénere capitalina" 60 .

Lazonby y Cía representa a aquellas empresas que lograron llegar hasta fines del siglo XX en Valparaíso. Se dedicaba a la importación en el ramo de hierros, aceros y diversos artículos para la construcción, como cemento, clavos y diversos artículos de ferretería. La casa se estableció en Valparaíso en 1886 como Lazonby y Campbell adoptando en 1902 el título con que destacó en la ciudad durante gran parte del siglo XX. Tuvo sucursal en Santiago ${ }^{61}$. Para 1924 la sociedad la constituían William Charles Lazonby, fundador de la firma, Jorge Fleming, P. L Peddar y

55 Escobar Aníbal, op. cit. El Príncipe de Gales..., 142.

56 Couyoumdjian, J. Ricardo, op. cit. 141.

57 RCV, 1931, Vol. 57, foj. 669.

58 RCV, 1933, Vol. 61, foj.1125.

59 Lloyd, Reginald, op. cit. 373.

60 Couyoumdjian, Juan Ricardo, "El Alto Comercio de Valparaíso y las Grandes Casas Extranjeras, 1880-1930, Una Aproximación”, Historia, N³3, 2000, 98.

61 Ibidem, 378. 
Agustín Viollier ${ }^{62}$. Para 1929 se reiteraban tres nombres como miembros de la sociedad habiéndose retirado Fleming. Reconocían un capital de \$1.000.000. Lazonby aportaba $\$ 449.000$; Peddar $\$ 400.000$ y Viollier $\$ 110.000^{63}$.

Relacionado con el funcionamiento de los ferrocarriles chilenos se estableció en Valparaíso la firma Schill; Seebohm \& Co Ltd. La casa matriz estaba en Manchester desde su creación en 1850. En Chile se establecieron a comienzos del siglo XX dedicándose a proveer al Estado de locomotoras, coches y vagones para los ferrocarriles estatales. Proveía además de máquinas a vapor, ascensores, cemento. Tenía en sus bodegas gran existencia de toda clase de maquinarias para elaborar metales, como tornos, taladros, motores a gas, trilladoras, molinos etc. Eran representantes exclusivos de importantes fábricas inglesas relacionadas con ferrocarriles y maquinarias industriales y agrícolas ${ }^{64}$.

Tal como hemos visto, muchas de las empresas establecidas en Valparaíso se relacionaban íntimamente con la actividad minera del norte. A las ya señaladas podemos agregar otra como Graham Rowe y Cía. que se estableció en Valparaíso en 1842 bajo la dirección de Charles Rowe. Como también poseían sucursal en Perú operaron exportando e importando en base a una triangulación Chile-PerúInglaterra. Entre los productos que manejaban estaban los explosivos, géneros, cemento, hierro galvanizado, etc. Desde Perú traían materia prima para la Refinería de Azúcar de Viña del Mar. Uno de los socios principales del establecimiento en Valparaíso fue John E. Naylor quien se mantuvo a la cabeza de la firma por más de 20 años. Naylor figuró también en otros directorios empresariales. Esta empresa poseía la agencia general en Valparaíso de la Anglo-Chilean Nitrate and Railway Co. de Tocopilla tanto para las remesas de herramientas, maquinarias y útiles diversos como para asuntos financieros 65 .

Otra empresa relacionada con la actividad salitrera fue Buchanan, Jones \& Co. que comenzó a operar en Iquique y Pisagua como H. B. James \& Co. participando en los negocios del salitre y yodo. Le correspondió construir y manejar a comienzos del siglo XX aproximadamente el $10 \%$ de los yacimientos salitreros existentes en el país y que pertenecían a la New Tamarugal Nitrate Co. Ltd. (oficinas La Palma y La Patria) y la London Nitrate Co. (oficinas Puntunchara, Tránsito). La oficina principal de la empresa se estableció en Valparaíso en donde manejaban los negocios de exportación e importación para lo cual disponían de la infraestructura apropiada. Fueron también agentes de compañías de seguros como la Union Marine Insurance Co. Ltd de Londres ${ }^{66}$. Hacia fines de la década de 1920 la firma giraba con un capital de 300.000 libras esterlinas y en las oficinas salitreras bajo su administración trabajaban alrededor de 6.000 personas ${ }^{67}$. En 1931 la firma se registra por un período de tres años declarando un capital de 350.000 libras esterlinas y

62 Escobar Aníbal, El Príncipe de Gales..., 161.

63 RCV, 1929, foj. 867.

64 Lloyd, Reginald, op. cit. 364.

65 Ibidem, 353.

66 Ibidem, 363.

67 Empresa Editorial Cronos, Chile en Sevilla... CLXXVIII. 
estaba constituida por Jorge Heriberto Jones Griffiths, Jorge Buchanan, Roberto Walterio Jones y Ricardo Ferreira que era de nacionalidad italiana ${ }^{68}$. Para 1933 la firma se fue a Santiago dejando las dependencias de Valparaíso en calidad de agencia ${ }^{69}$. Para entonces la sociedad estaba constituida por Jorge y Roberto Jones y Ricardo Ferreira ${ }^{70}$.

Había también otros rubros entre los cuales era posible ubicar empresarios británicos como es el caso de Fraser y Southward, químicos ingleses que poseían un laboratorio en donde se elaboraban diversos productos químicos y se realizan diversos ensayos ${ }^{71}$. Dedicada a la comercialización de vinos y bebidas espirituosas encontramos a Reginald Bushell junto a Edward J. H. Ash quienes representan a diversas viñas chilenas, entre ellas Viña Santa Rita y Chacra Ochagavía. Los escoceses David Steward, Ramsay Gordon y Andrew Henderson abrieron en 1876, en calle del Cabo una librería-papelería. Cinco años después de la fundación en vista del crecimiento que tenía el establecimiento se incorporó un nuevo socio, J W. Hardy quien en 1890 quedó como único propietario. Durante el siglo XX se realizaron ampliaciones importantes asumiendo funciones de casa mayorista que se conoció con la razón de Hardy Menelaus \& $\mathrm{Co}^{72}$. Cabe señalar que Hardy fue también presidente de la Compañía de Gas. Otro establecimiento de librería perteneciente a un británico fue la librería e imprenta inglesa de James Loutit y que fue fundada en 1855 por Roberto Struthers pasando por diversos dueños hasta quedar en poder de Loutit quien la manejó gran parte del período que nos interesa. R. Magowan incursionó también en el negocio de librerías como también productos deportivos. Holbrook y Tyrer fueron importadores especializados en artículos náuticos. Thomas Crangle abastecía de carne a los barcos para lo cual traía ganado desde Argentina. El escocés Alejandro Macnab se dedicó a instalaciones de alumbrado, agua potable y calefacción.

\section{DESARROLLO INDUSTRIAL}

A fines del siglo XIX se percibe un importante desarrollo industrial en nuestro país. Valparaíso como una de las ciudades más importantes de la época refleja esta situación mostrándose como un centro industrial sobresaliente. El principal puerto del país reúne un importante número de industrias que en el plano comparativo muestran un nivel de desarrollo técnico más avanzado que el resto del país incluyendo Santiago.

Sin duda que el sector más sobresaliente es el metalmecánico que en su condición de productor de bienes durables y de capital se inserta en un nivel de desarrollo tecnológico superior al estado promedio del proceso industrial nacional que se

68 RCV, 1931, Vol. 57, foj. 1149

69 RCV, 1933, Vol. 60, foj. 254.

70 RCV, Vol. 60, 1933, foj. 254

71 Escobar, Aníbal, Gran Bretaña en Chile... 251.

72 Lloyd, Reginald, op. cit. 379. 
identifica más con la producción de bienes de consumo y que corresponde fundamentalmente al rubro alimentario.

Nuestro desarrollo industrial en sus niveles más evolucionados no fue fruto de un proceso endógeno y por el contrario su evolución no fue sino provocada por factores exógenos. De este modo se percibe una total asincronía entre el desarrollo industrial y el desarrollo económico-social del país. En esta perspectiva los británicos jugaron un papel destacado que merece nos detengamos en su análisis

Diversos trabajos han demostrado que luego de la Guerra del Pacífico en Chile se puede sostener que existe un proceso de industrialización. Sin embargo persisten otros aspectos relacionados al papel que este sector desempeña dentro de la economía del país. En verdad, la industria no logró, pese a su desarrollo, transformarse en un polo de desarrollo que impactará el resto de la estructura económica del país, es decir, no desempeñó el papel de liderazgo que se reconoce en Europa luego de la revolución industrial. Se suponía que logrado un determinado nivel de desarrollo industrial automáticamente se produciría un efecto en cadena que afectaría a los restantes sectores que se incorporaban a un proceso dinámico de modernización.

Hasta los años sesenta se desconoció, por diferentes autores, la existencia de un proceso industrial en Chile. Habría que ser más justos con todos ellos en cuanto a que en cierto sentido tenían razón en su percepción si nos referimos a la industrialización como un proceso que se ha generado como consecuencia natural del desarrollo económico global del país. Efectivamente tal situación no ocurría. La existencia de las industrias hasta 1930 se caracterizó por la inestabilidad y fuerte dependencia del desarrollo económico externo.

En un plano cuantitativo y en un análisis sectorial, la industria revela una evolución significativa pero no muestra solvencia y estabilidad si se consideran sus relaciones con los restantes sectores productivos y si se consideran las características macroeconómicas del país. Del mismo modo surgen las debilidades cuando entramos a analizar la forma como se manifiestan los diversos factores productivos dentro del sector industrial.

El particular desarrollo de Valparaíso durante el siglo XIX explica la posición protagónica que tiene para ese período. El creciente desarrollo comercial y posteriormente financiero que se controla desde el principal puerto del país genera un crecimiento demográfico y un dinamismo económico sin parangón en el resto del país. La aventajada posición para relacionarse con el extranjero y también con el resto del país privilegian su posición para el desarrollo industrial. Por otro lado, la fuerte presencia extranjera en la ciudad que hegemoniza la actividad económica hace propicio el ambiente para incursionar en nuevas arreas del quehacer económico. En general se puede decir que Valparaíso muestra, como sociedad, un aspecto más proclive a la modernización, frente al resto del país. Considerando todos estos factores no es extraño que se concentre en Valparaíso un centro industrial con características sobresalientes para fines del siglo XIX.

Entre las ventajas comparativas de Valparaíso, además de su posición geográfica, habría que agregar la misma función portuaria que exigía ciertos quehaceres relacionados fundamentalmente con la mantención de naves. Es así como los pri- 
meros testimonios sobre la existencia de establecimientos del sector metalúrgico mecánico muestran a Valparaíso desde mediados de siglo como una zona de concentración de tales establecimientos.

Una primera percepción de las características de estas industrias es que mayoritariamente pertenecen a extranjeros. También es importante destacar la participación del Estado en el caso de la maestranza del ferrocarril y del ejército que se estableció en Limache y que se originó como necesidad de abastecer al ejército ante el conflicto bélico con los españoles. Esta industria pese a que tuvo un gran desarrollo no prosperó por limitaciones presupuestarias, decidiéndose su clausura.

El desarrollo de la actividad industrial metalmecánica estuvo muy vinculada a la actividad minera y el desarrollo de las obras estatales. Es así como el abastecimiento de maquinarias y repuestos requeridos por las salitreras permitió una actividad importante de las fundiciones nacionales. Por otro lado, el Estado con el desarrollo del ferrocarril y de las obras públicas hizo posible que en el país se pudieran construir locomotoras, carros, puentes y diversos implementos propios del desarrollo del transporte y obras públicas. También debemos considerar los requerimientos propios de las faenas portuarias y el transporte marítimo. Hay casos incluso de construcción de naves pero sin duda lo más habitual es la reparación y mantención naviera. Hay momentos coyunturales que permitieron mayor actividad del sector. Como ocurre para la Guerra del Pacífico y el conflicto con España. Asimismo las crisis internacionales que afectaron el transporte y comercio internacional trajeron también nocivas consecuencias para el país sobre todo para las industrias que tenían un alto grado de dependencia de insumos externos.

Es notable la concentración que muestra Valparaíso, a fines del siglo XIX, de establecimientos metalmecánicos en relación al resto del país, superando ampliamente en calidad a los de Santiago ${ }^{73}$. Esta situación se advierte desde el momento mismo de lograda la independencia de España.

Del mismo modo llama la atención el predominio que muestran los extranjeros, especialmente los británicos, como asimismo la fuerte dependencia de insumos importados. Todos estos elementos, sumado a la existencia de un mercado limitado, inestable y de abultada dependencia económica y cultural de Europa, atentaron en contra de la conformación de un sector industrial que empujara al resto de la economía nacional.

$\mathrm{Si}$ analizamos estas características podemos concluir que la industria metalmecánica era muy inestable en sus posibilidades de desarrollo. Por un lado, dependía de un mercado muy inestable, como la actividad minera, y del Estado que también tenía un comportamiento poco regular por las crisis y creciente inflación que afectaba sus presupuestos. De allí entonces que si bien encontramos momentos en que las fundiciones desarrollaban trabajos muy importantes que les obligaba a concentrar una importante masa laboral había también momentos en que esto no ocurría debiendo estas industrias despedir mano de obra calificada muchas veces traída del

73 Estrada, Baldomero. "Valparaíso y el Proceso de Industrialización en Chile a fines del Siglo XIX”, en Varios Autores, Valparaíso 1536-1986, Serie Monografías Históricas, Universidad Católica de Valparaíso 1987. 
extranjero. Esta situación inhibía las posibilidades de desarrollo tecnológico en un sector muy dinámico lo que a mediano plazo constituyó la razón de la decadencia de su evolución. La incapacidad para competir con el desarrollo tecnológico internacional fue al final una de las causas principales de su decadencia.

También, si consideramos que cerca del $70 \%$ de la materia prima se obtenía del extranjero el grado de dependencia y los elevados costos imponían barreras difíciles de salvar. En este aspecto es importante señalar las serias dificultades que tuvo el país para estimular la industria del acero, producto fundamental para el progreso del sector.

En cuanto a las características del empresariado y de la mano de obra especializada se revela también, con la presencia extranjera, las debilidades que tenía la educación técnica en Chile para proporcionar trabajadores apropiados para desempeñarse en labores de alta especialización. Era habitual escuchar a los empresarios de estas industria quejarse por las dificultades que tenían para encontrar obreros capacitados. De allí la necesidad de traerlos desde el extranjero elevando los costos y quedando expuestos a la posibilidad de perderlos cuando no existiera la demanda adecuada del mercado local ${ }^{74}$.

Es evidente que el crecimiento que muestra este sector industrial refleja las anomalías que expresaba el proceso de industrialización nacional que por lo demás en sus vínculos con el comportamiento de la economía nacional estaba sometida a una situación extremadamente débil.

El auge del sector metalmecánico no se produjo en forma paralela al resto de la industria, estuvo unido a determinadas circunstancias que no reflejaban el comportamiento de la economía global. Las grandes realizaciones de la industria metalmecánica como la construcción de locomotoras y naves fueron más bien esfuerzos aislados y excepcionales que no llegaron a permitir la configuración de una industria estable autosostenida . La evolución cíclica que imponía la inestabilidad del mercado nacional no podía generar la estabilidad y posibilidades de inversiones sobre todo en tecnología, que imponía el sector metalmecánico para estar en niveles competitivos con la industria internacional.

Por todo lo anterior es que el importante adelanto que tiene la industria metalmecánica en Valparaíso desde mediados de siglo XIX hasta comienzos del XX debemos considerarlo como un proceso ajeno a nuestra propia expansión y más bien vinculado a lo que fue el papel que los ingleses tuvieron en nuestra economía. La información que nos entregan las fuentes oficiales de mediados del siglo XIX dejan en evidencia el absoluto dominio que tienen los europeos en el control de los establecimientos artesanales vinculados con la metalmecánica. Las carrocerías, herrerías y hojalaterías están controladas por británicos, alemanes y franceses. En el caso de los británicos encontramos a J. Reynolds, A. Oswald, Cameron \& Young, Mouat \& Borrowman, Henderson-Finch, R.J. Grove, Carley y Campbell, T. Rider, Lucker \& Rider, Brown \& Darley ${ }^{75}$. A fines del siglo XIX se notó una evolución

\footnotetext{
74 Estrada, B. "Valparaíso y el Proceso ...".

75 Matrícula del Comercio según Registro de Patentes tomadas en 1857.
} 
importante que permite encontrar industrias bastante desarrolladas en tecnología y tamaño dentro del contexto industrial que tenía el país, de tal modo que podíamos ver empresas que agrupaban importante número de obreros como era el caso de las fundiciones de Juan Morrison, Balfour-Lyon, Ricardo Lever, A. C. Brower, T. Borrowman, Harper e Hijos. En el caso de la "Fundición de Chile" perteneciente a R. Lever y Murphy; la "Fundición La Unión", de propiedad de A. C. Brower y la "Fundición La Victoria" de Balfour Lyon poseían en promedio sobre 400 obre$\operatorname{ros}^{76}$. De entre todas estas empresas, que pertenecían a británicos, haremos una breve reseña de la fábrica que impulsó especialmente Ricardo Lever. En el conocimiento de su evolución podremos conocer los avatares que afectaron a este sector industrial.

En 1859 se instaló un taller de calderería en la calle Arsenal de Valparaíso perteneciente a Ricardo Lever, Norman Ferguson y Guillermo Murphy. Posteriormente, como consecuencia del crecimiento del establecimiento, en 1883, se vieron en la obligación de mudarse y se trasladaron hasta Caleta Abarca en Viña del Mar. Durante la Guerra del Pacífico repararon todas la máquinas de la Escuadra Nacional para lo cual trajeron maquinaria y obreros especializados desde Inglaterra. Posteriormente, con la ayuda del gobierno de Balmaceda tuvieron una importante participación en la construcción de material ferroviario lo que determinó un importante impulso para la industria. En 1887 construyeron la primera locomotora a la cual como un homenaje al Presidente de la República pusieron su nombre. Después le siguieron varias otras ${ }^{77}$. Esta industria en determinados momentos llegó a tener más de 800 obreros trabajando, específicamente cuando debió cumplir contratos con Ferrocarriles del Estado, sin embargo hubo ocasiones en que la demanda escaseaba e impedía mantener a los obreros especializados, muchos de los cuales fueron traídos directamente desde Inglaterra y por último era difícil recuperarlos. De allí las declaraciones del propio Lever, quien hace notar que si bien es efectivo que en 1888 tuvieron una planta de 550 obreros, para 1889 tenían solo 320, ya que se vieron en la obligación de despedir a muchos de los que anteriormente habían contratado y hacía notar que "muchos de ellos se han ido al extranjero, de donde los hicimos venir a costa de muchos sacrificios, pues necesitábamos operarios entendidos en el manejo de mucha maquinaria especial implantada para la construcción de locomotoras. Cada uno de estos obreros contratados en Inglaterra demandó un gasto de mil pesos solamente en el pasaje. Los obreros extranjeros han servido de profesores para los trabajadores del país" ${ }^{78}$. El desarrollo de la industria determinó un incremento de capitales y un cambio de nombre pasando a identificarse como Sociedad de Maestranzas y Galvanización.

Además de los trabajos esporádicos que representaban las órdenes estatales la empresa se sostenía con trabajos que efectuaba como astillero y la construcción de

76 Memoria del Ministerio del Interior presentada al Congreso Nacional en 1885; Rigoberto García, Incipient Industrialization in an Underdeveloped Country. The Case of Chile, 1845-1879, Institute of Latin American Studies, Monograph N 17, Stockolm 1989.

77 La Producción Nacional, Valparaíso, 1 de abril 1905.

78 Boletín de la Sociedad de Fomento Frabril. $\mathrm{N}^{\circ}$ 6, 1889, 247. 
máquinas y herramientas para la minería. Para las faenas salitreras construían, entre otros productos, grandes estanques o cachuchos empleados para la elaboración del mineral. Para los ferrocarriles también construyeron diversos puentes que aún se mantienen en funcionamiento y entre los cuales destacan el "Maule", "Lircay", "Ñuble y "Perquilabuquen"79.

En 1901, entre los diversos trabajos realizados a petición de la Armada, construyeron la nave Meteoro que fue el primer buque a vapor construido en Chile, habiendo sido sus máquinas construidas íntegramente en los talleres de la industria ${ }^{80}$. Del mismo modo construyeron las dos calderas de la corbeta Abtao que fue durante mucho tiempo, el buque escuela de la Armada Nacional. También se construyeron varios faros y un vapor para el servicio de faros. Para 1909 había construido 480 carros, 60 calderos, 100 pares de cilindros, 34 locomotoras, 6 vapores, 20 lanchas, 5 faros de hierro y varias instalaciones completas para salitreras ${ }^{81}$.

Entre las obras realizadas en la ciudad podemos mencionar el muelle Vergara, que durante muchos años fue utilizado por la Refinería de Azúcar de Viña del Mar, industria que figuraba entre sus principales clientes y que dispuso de una de las tantas locomotoras que se construyeron por esta destacada fábrica británica y que hoy se exhibe en la Av. Altamirano en Viña del Mar ${ }^{82}$. Para esta industria construyó también, en 1928, a fin de facilitar el tráfico ferroviario sobre el estero MargaMarga, el puente Cancha. Al siguiente año levantó un edificio al interior de la industria azucarera de 640 metros $^{83}$.

Para 1914, en plena guerra mundial, la prensa informaba de lo decadente que se encontraba la industria en el principal puerto nacional y aunque la Sociedad Maestranzas y Galvanización no estaba entre las más afectadas mostraba evidentes síntomas de decadencia y apremios económicos. Se hacía notar la deuda de medio millón de pesos oro por parte del Estado por la construcción de 12 locomotoras y la notable disminución de obreros que, de acuerdo a la situación, se acentuaría a futuro. Se indicaba, como ejemplo que en la sección armaduría anteriormente trabajaban 80 operarios, pero que se había reducido a la mitad de esa cifra ${ }^{84}$. En 1918 amplió el giro de sus negocios con la formación de la sección automóviles aumentándose para esto el capital ${ }^{85}$. La decadencia de la industria salitrera y la falta de trabajo entregado por parte del Estado provocaron una lenta decadencia de la industria, tal como se lo informaron al Presidente Alessandri en su visita a la industria en marzo de 1923 y quien no se comprometió a ayudar a revertir la situación argumentando la falta de apoyo que tenía de parte del senado para sus proyectos ${ }^{86}$.

\footnotetext{
79 Idem. $\mathrm{N}^{\circ} 12,1905,45$.

80 El Mercurio de Valparaíso, 23 de noviembre de 1901.

81 Boletín de la Sociedad de Fomento Frabril. $\mathrm{N}^{\circ}$ 16, 1909, 222.

82 Lloyd, Reginald, op. cit. 346.

83 Carolina Miranda, "La Inserción de la Fábrica Lever Murphy y Cia en Viña del Mar", en: Varios Autores, Lever Murphy y Cia. Historia de una Empresa Viñamarina. 1883-1936 (trabajo inédito). Agradecemos a Eugenia Garrido quien nos facilitó esta versión.

84 El Mercurio de Valparaíso, 20 de agosto 1914.

85 "La Sociedad de Maestranzas y Galvanización”, en: Zig-Zag N843.

86 El Mercurio de Valparaíso, 6 de marzo de 1923.
} 
En 1926 la industria fue transferida a la United Steel Products Co ${ }^{87}$. Para 1929 la empresa giraba con un capital de $\$ 2.700 .000^{88}$. Finalmente la industria tuvo que desaparecer ante los proyectos de desarrollo turístico que impuso el municipio viñamarino en 1936, cuando no se le renovó la concesión de uso del amplio terreno que hoy ocupa el balneario de Caleta Abarca y el Hotel Miramar89.

Sin duda que la industria creada por Lever \& Murphy constituyó una excepción dentro del contexto industrial nacional y los avatares que tuvo que enfrentar reflejaron las peripecias que imponía nuestra evolución económica. Guillermo Murphy murió en 1894, cuando la empresa había alcanzado un significativo desarrollo. Como la mayoría de los ingleses establecidos en Chile había formado su familia con una compatriota que estuvo a su lado en su hogar establecido en Viña del Mar. Por su parte, Ricardo Lever G. falleció en 1923, en Limache, cuando estaba casado con Matilde Knight que pertenecía también a la colectividad británica ${ }^{90}$. Cabe señalar que anteriormente estuvo casado con Juana Cáceres, chilena, con quien tuvo seis hijos. En la ocasión en que redacta su testamento, 1896, declara que posee como bienes $\$ 600.000$ por la parte correspondiente a su participación en la industria además de una casa en Valparaíso, otra en Viña del Mar y un sitio en Lo Chaparro (Limache). Hace notar que todos sus bienes los adquirió durante su matrimonio con lo cual deja establecido que no trajo mayor capital al momento de llegar y que todo cuanto consiguió fue el fruto del trabajo realizado en Chile ${ }^{91}$.

Entre las industrias metalmecánicas que pertenecían a la colectividad británica que figuran durante el siglo XX no podemos dejar de mencionar a Balfour Lyon, la cual pese a las dificultades se mantuvo a través del tiempo aunque disminuyó su potencial el relación a lo que alcanzó a comienzos del siglo XX. Se gestó en forma muy modesta como Fundición Victoria en 1849. Un progresivo desarrollo tecnológico y un ejercicio eficiente llevaron a la empresa a figurar entre las fundiciones más calificadas del país. Para 1909 informaban que para Ferrocarriles del Estado había construido en los últimos años 30 coches, 30 carros de 30 toneladas, 30 carros de 20 toneladas, 10 carros planos de 20 toneladas, 30 carros de 8 toneladas, 4 locomotoras, 35 calderos para locomotoras y diversas piezas para motores ${ }^{92}$. Para 1915 tenía una dotación obrera disminuida por los problemas bélicos europeos pero en sus mejores tiempos llegó a tener una planta de 500 operarios. En 1936 declaraban un capital de 90.000 libras esterlinas y la sociedad estaba constituida por 11 socios y solo uno de ellos no era británico ${ }^{93}$. En 1946, los socios eran 14, todos miembros de la colectividad británica, y contaban con un capital de 15.000.000 de pesos $^{94}$.

87 La Unión, Valparaíso, 23 de octubre de 1926.

88 Empresa Editorial Cronos, op. cit. CLIV.

89 Flavio Bauman, "Una Empresa Emblemática del Sector Matalúrgico Chileno, 1883-1936" (inédito), en: Varios Autores, Lever Murphy y Cia. Historia de una Empresa Viñamarina...

90 Ibidem.

91 Testamento de Ricardo Lever, 9 de mayo 1896. Notaría de Enrique Gana.

92 Boletín de la Sociedad de Fomento Frabril. N $^{\circ} 16$, 1909, 223.

93 RCV, 1936.

94 RCV, 1946, Vol. 835. 
Entre las figuras destacadas como ingeniero mecánico cabe señalar a John Morrison que llegó al país contratado por la Armada de Chile en 1858. Pronto se independizó y se integró a la sociedad Cuthill \& Morrison Co. Posteriormente creó su propia empresa a la que se integraron sus hijos. Un incendio destruyó sus talleres en 1904, los reconstruyó pero nuevamente una desgracia echó por tierra sus esfuerzos ya que los incendios provocados por el terremoto de 1906 pusieron término a su industria. A partir de entonces se dedicó a trabajar como profesional y vendiendo maquinaria importada. Sus hijos se mantuvieron también trabajando como profesionales dentro del rubro ${ }^{95}$. Figura importante, en esta área industrial, fue también Robert Campbell quien llegó a Valparaíso en 1880 para desempeñarse profesionalmente en los establecimientos de Lever \& Murphy. Posteriormente se empleó como $2^{\circ}$ ingeniero en los vapores de la Cía. Errázuriz, propietarios de las minas de carbón de Lebu. Luego trabajó, durante nueve años, en la fábrica de Balfour Lyon para enseguida ocuparse como ingeniero mecánico en jefe de las minas Schwager, Maule y Coronel de donde se retiró, al cabo de siete años, en 1898 , para asociarse con Guillermo Griffiths y establecer una fundición que posteriormente poseyó en forma individual. Se especializó en reparaciones de naves y diversos trabajos relacionados con su profesión ${ }^{96}$.

Sin duda que al hablar de la evolución de la industria metalmecánica en Valparaíso y todo el país necesariamente debemos considerar en posición destacada la labor de los británicos. Si bien estuvo vinculada al desarrollo minero y sujeta a sus vaivenes su aporte fue significativo y excepcional frente a la impronta comercialfinanciera que marcó al quehacer de la colectividad en nuestro país.

Dentro del sector industrial debemos también señalar la presencia de la British American Tobacco que se fundó en marzo de 1922 con un capital de \$400.000. El directorio que tenía esta empresa en 1923 estaba compuesto por Cecil Edwards, Arthur Saunders, Claude Stephens y el gerente era John Ogilvie Davis ${ }^{97}$. Esta industria fue el origen de la Cía. Chilena de Tabacos que permanece hasta hoy y que aún mantiene capitales de origen británico. Del mismo modo la fábrica de velas "Precias" fue también un aporte industrial importante par la industria nacional dentro de un rubro poco identificado con los británicos. Esta empresa fue fundada en 1913 con dos plantas, una en Valparaíso y otra en Concepción. En Valparaíso poseía una planta de obreros y empleados sobre las 60 personas ${ }^{98}$.

Por la relación que tuvo con el comercio internacional es pertinente también señalar la importancia de la Cía. Sudamericana de Vapores que entre sus fundadores aparecen destacados miembros de la colectividad británica. En el primer directorio constituido por 6 miembros encontramos a Santiago Lyon Santa María y Jorge Ross. Como gerente fue designado Alfredo Lyon Santa María y subgerente Horacio Lyon Santa María. La presencia de los hermanos Lyon, hijos de un migrante que llegó, desde Inglaterra en la década de 1820, con solo 21 años de edad,

95 Lloyd, Reginald, op. cit. 361.

96 Escobar, Aníbal, Gran Bretaña en Chile, 254.

97 Ibidem, 238.

98 Escobar, Aníbal, El Príncipe de Gales, 162. 
sin recursos y solo los deseos de triunfar, marcó durante muchos años a la compañía que se constituyó en un instrumento vital para el tráfico marítimo ${ }^{99}$. Comenzó con una flota de 7 naves y mandó a construir 4 adicionales. Comenzó sus operaciones realizando comercio de cabotaje para luego ampliar su radio de acción hasta Callao, y posteriormente Guayaquil y Panamá. La evolución de esta empresa implicó diversos problemas que supo sortear adecuadamente. Entre ellos las huelgas del sector marítimo que aunque no siempre eran propiamente de la compañía le afectaban como fue el caso del conflicto de los lancheros en mayo de 1897. Distinta es la situación para la famosa huelga de 1903, que estuvo dirigida específicamente contra las compañías navieras y que terminó con el incendio del edificio de la Compañía ${ }^{100}$. En el plano de la competencia tuvo que bregar constantemente, en especial, con la labor de la Pacific Steam Navegation Co. y la Kosmos. A comienzos del siglo XX la Compañía mantuvo tres líneas de navegación: de Valparaíso a Nueva York (ruta que se realizaba en 14 días); de Valparaíso a Guayaquil y de Valparaíso a Lota con salidas semanales. Su planta estaba constituida por 250 empleados y 800 operarios $^{101}$. Para la década de 1920 encontramos en el directorio de la empresa una representación importante aún de miembros de la colectividad británica como Edmundo Eastman, Carlos Finlay, Guillermo Brown, Ismael Edwards, Edmundo Compton. El período comprendido entre 1920 y 1932 fue una etapa muy dura para la empresa como efecto de los problemas económicos en el ámbito local por la decadencia del salitre y luego por la crisis internacional que explotó en 1929. Posteriormente vino un proceso de crecimiento que se tradujo en la compra de nuevas naves y abriendo nuevas rutas. En 1938 se abrió el servicio a Europa $^{102}$, pero una vez declarada la guerra las naves que cubrían ese servicio se trasladaron a la ruta Valparaíso-Nueva York. Posteriormente la empresa fue cambiando la composición del directorio lo que significó un alejamiento de descendientes de británicos de sus filas.

Por su parte la Pacific Steam Navegation Co. que fue fundada en 1840 iniciando la navegación a vapor en nuestras costas, fue también un importante testimonio de lo que fue la presencia británica en el comercio internacional en nuestras costas. Durante los primeros cinco años entregó servicios entre Talcahuano y Callao. Su desempeño abarcó diversos rubros ya que además del transporte de carga y valija tuvo especial interés por el traslado de pasajeros estableciendo algunas rutas con fines turísticos para lo cual dispuso de naves apropiadamente adecuadas para tales objetivos. Igualmente tuvo un contrato con el gobierno para transportar oficiales del ejército y personal que se desempeñaba para el Estado ${ }^{103}$. Fue la primera de las empresas navieras que realizó exportaciones de frutas chilenas con cámaras frigoríficas durante la década de 1920. Para entonces el gerente de la Cía. era Thomas

99 Gonzalo Vial C. et al, La Sudamericana de Vapores en la Historia de Chile, Imprenta Salesianos, Santiago 1997, 58-59.

100 Allard, Jorge, 100 Años de la Compañía Sudamericana de Vapores. 1872-1972, s/f., 64

101 Empresa Editora Cronos, op. cit., CLXII.

102 Allard, Jorge, op. cit. 100.

103 Centner, Charles William, Great Britain, 1810-1914: A Chapter in the Expansion of Europe Ph D Dissertation, University of Chicago 1941, 197. 
Lindar ${ }^{104}$. En 1923 la Compañía representaba los dos tercios de todos los barcos que entraban al Reino Unido desde las costas del Pacífico sudamericano ${ }^{105}$.

Dentro de los ámbitos en los cuales es posible advertir la presencia británica debemos también mencionar su participación en los diferentes servicios públicos, que funcionaban en la ciudad. Bien sabemos que desde el siglo XIX el transporte ferroviario recibió un fuerte apoyo de parte de los británicos por lo que significó la presencia de destacados profesionales de ese origen. Para el caso del tramo Valparaíso Santiago sobresalieron Roberto Campbell (mencionado anteriormente) y William Lloyd a quien correspondió abrir el túnel en Punta Gruesa que fue el primer túnel ferroviario construido en Sudamérica y posteriormente destruido para dar paso al camino que unió Valparaíso con Viña del Mar ${ }^{106}$. El desarrollo de servicios tales como la electricidad, telefonía, electricidad, desagüe, pavimento vial cuentan en sus orígenes con la participación de empresarios británicos. Un caso aparte al respecto lo constituyeron los trabajos que realizaron en las obras portuarias cuya relevancia para el crecimiento comercial y por ende para el desarrollo de la ciudad fue muy importante.

Fecha de recepción: noviembre de 2005.

Fecha de publicación: junio de 2006.

104 Escobar, Aníbal, El Príncipe de Gales..., 170.

105 Centner, Charles, op . cit. 200.

106 R.P. Hillman, Británicos y sus Descendientes en la Historia y Vida de Chile (versión mecanografiada), 160 . 


\section{TABLA N ${ }^{\circ} 1$}

ESTRUCTURA LABORAL DE LA COLECTIVIDAD BRITÁNICA DEPARTAMENTO DE VALPARAÍSO. 1895

\begin{tabular}{|c|c|c|c|c|c|c|c|}
\hline \multicolumn{2}{|c|}{ SECTOR PRIMARIO } & \multicolumn{3}{|c|}{ SECTOR SECUNDARIO } & \multicolumn{3}{|c|}{ SECTOR TERCIARIO } \\
\hline Sexo & M & Sexo & $\mathrm{H}$ & M & Sexo & $\mathrm{H}$ & M \\
\hline \multirow[t]{25}{*}{ Agricultores } & 0 & Caldereros & 3 & 0 & Abastecedores & 1 & 0 \\
\hline & & Carboneros & 4 & 0 & Agentes Comerciales & 8 & 0 \\
\hline & & Carpinteros & 8 & 0 & Arquitectos & 1 & 0 \\
\hline & & Cocineros & 9 & 8 & Artistas & 1 & 0 \\
\hline & & Constructores & 4 & 0 & Comerciantes & 201 & 2 \\
\hline & & Ebanistas & 1 & 0 & Eclesiásticos & 2 & 0 \\
\hline & & Electricistas & 7 & 0 & Empleados Públicos & 2 & 0 \\
\hline & & Empresarios & 2 & 0 & Empleados Particulares & 212 & 5 \\
\hline & & Encuadernadores & 1 & 0 & Estudiantes & 10 & 0 \\
\hline & & Farmacéuticos & 1 & 0 & Fleteros & 3 & 0 \\
\hline & & Fogoneros & 22 & 0 & Gañanes & 6 & 0 \\
\hline & & Grabadores & 1 & 0 & Hoteleros & 1 & 0 \\
\hline & & Herreros & 11 & 0 & Ingenieros & 54 & 0 \\
\hline & & Hojalateros & 1 & 0 & Marinos & 337 & 0 \\
\hline & & Industriales & 2 & 0 & Médicos & 2 & 0 \\
\hline & & Maquinistas & 2 & 0 & Militares & 1 & 0 \\
\hline & & Mecánicos & 49 & 0 & Ministros Disidentes & 1 & 0 \\
\hline & & Modistas & 0 & 1 & Profesores Música & 1 & 0 \\
\hline & & Panaderos & 6 & 0 & Profesores & 18 & 11 \\
\hline & & Pintores & 2 & 0 & Religiosas & 0 & 2 \\
\hline & & Relojeros-Joyeros & 2 & 0 & Rentistas & 13 & 7 \\
\hline & & Sastres & 6 & 5 & Sirvientes & 11 & 24 \\
\hline & & Talabarteros & 1 & 0 & Telefonistas & 1 & 0 \\
\hline & & Tipógrafos & 3 & 0 & Telegrafistas & 8 & 0 \\
\hline & & Zapateros & 1 & 0 & Vendedores Ambulantes & 1 & 0 \\
\hline Subtotal & 0 & & 148 & 14 & & 896 & 51 \\
\hline Total por sector & 2 & & & 162 & & & \\
\hline Total hombres & 1.046 & & & & & & \\
\hline Total mujeres & 65 & & & & & & \\
\hline Total & 1.111 & & & & & & \\
\hline
\end{tabular}

Fuente: Censo de República de Chile para el año indicado. 